\title{
Inhibition of A/Human/Hubei/3/2005 (H3N2) influenza virus infection by silver nanoparticles in vitro and in vivo
}

This article was published in the following Dove Press journal:

International Journal of Nanomedicine

29 October 2013

Number of times this article has been viewed

\author{
Dongxi Xiang' \\ Yang Zheng ${ }^{2}$ \\ Wei Duan' \\ Xiujing $\mathrm{Li}^{3}$ \\ Jianjian Yin ${ }^{3}$ \\ Sarah Shigdar' \\ Michael Liam O'Connor' \\ Manju Marappan' \\ Xiaojuan Zhao ${ }^{4}$ \\ Yingqiu Miao ${ }^{3}$ \\ Bin Xiang ${ }^{5}$ \\ Conglong Zheng ${ }^{3}$ \\ 'School of Medicine, Deakin University, \\ Waurn Ponds, Victoria, Australia; \\ 2Department of Pharmacology, Osaka \\ University, Osaka, Japan; ${ }^{3}$ Department \\ of Biology, Medical College, Dalian \\ University, Liaoning, People's Republic of \\ China; ${ }^{4}$ Department of Gynaecology and \\ Obstetrics, Qingdao Central Hospital, \\ Shandong, People's Republic of China; \\ ${ }^{5}$ Department of Oral Medicine and Medical \\ Research Center, Medical College, Dalian \\ University, Liaoning, People's Republic of \\ China
}

Correspondence: Dongxi Xiang

School of Medicine, Deakin University,

Waurn Ponds, Victoria 3217, Australia

Tel +6I452565738

Email dxiang@deakin.edu.au

Conglong Zheng

Department of Biology, Medical College,

Dalian University, 10 Xue Fu St,

Dalian II6622, Liaoning,

People's Republic of China

Tel +86 4II 87402353

Fax +86 4I I 87402050

Email zhengconglong@dlu.edu.cn
Abstract: Silver nanoparticles (AgNPs) have attracted much attention as antimicrobial agents and have demonstrated efficient inhibitory activity against various viruses, including human immunodeficiency virus, hepatitis B virus, and Tacaribe virus. In this study, we investigated if AgNPs could have antiviral and preventive effects in A/Human/Hubei/3/2005 (H3N2) influenza virus infection. Madin-Darby canine kidney cells infected with AgNP-treated H3N2 influenza virus showed better viability ( $P<0.05$ versus influenza virus control) and no obvious cytopathic effects compared with an influenza virus control group and a group treated with the solvent used for preparation of the AgNPs. Hemagglutination assay indicated that AgNPs could significantly inhibit growth of the influenza virus in Madin-Darby canine kidney cells $(P<0.01$ versus the influenza virus control). AgNPs significantly reduced cell apoptosis induced by H3N2 influenza virus at three different treatment pathways $(P<0.05$ versus influenza virus control). H3N2 influenza viruses treated with AgNPs were analyzed by transmission electron microscopy and found to interact with each other, resulting in destruction of morphologic viral structures in a time-dependent manner in a time range of 30 minutes to 2 hours. In addition, intranasal AgNP administration in mice significantly enhanced survival after infection with the H3N2 influenza virus. Mice treated with AgNPs showed lower lung viral titer levels and minor pathologic lesions in lung tissue, and had a marked survival benefit during secondary intranasal passage in vivo. These results provide evidence that AgNPs have beneficial effects in preventing $\mathrm{H} 3 \mathrm{~N} 2$ influenza virus infection both in vitro and in vivo, and demonstrate that AgNPs can be used as potential therapeutics for inhibiting outbreaks of influenza.

Keywords: silver nanoparticles, influenza virus, H3N2, antiviral activity

\section{Introduction}

Among the leading global infections, influenza is a major cause of morbidity and mortality, periodically causing recurrent epidemics or global pandemics that can result in approximately $20 \%$ of the world's population becoming ill. ${ }^{1,2}$ Influenza viruses (IFVs) are negative-stranded RNA viruses, belonging to the family Orthomyxoviridae. They are classified into different serotypes based on the antigenicity of their hemagglutinin (16 subtypes, H1-H16) and neuraminidase (nine subtypes, N1-N9) molecules, but H1, $\mathrm{H} 2$ and $\mathrm{H} 3$, and N1 and N2 are commonly represented in humans. ${ }^{3,4}$ Antigenic drift occurs when small mutations emerge in hemagglutinin or neuraminidase antigens, and is distinct from genetic shift whereby completely new strains can emerge when different IFV strains recombine with each other. ${ }^{5-7}$ Either antigenic mutation or reassortment can result in novel pathogenic IFV strains with the capacity to cause new epidemics or worldwide pandemics. ${ }^{1}$ Many influenza variants have evolved and have the potential 
to develop resistance to antiviral drugs. Currently, the two main strategies used to control the prevalence of influenza are injectable vaccines and antiviral agents. However, IFV vaccination would have little efficacy in the early stages of an epidemic, especially one generated by genetic shift with a new virus subtype. ${ }^{1,8}$ The two classes of antiviral agents widely used against influenza at present are the M2 channel blockers (adamantane derivatives) and neuraminidase inhibitors (oseltamivir and zanamivir), but their long-term effectiveness against IFV is debatable and limited by increasing emergence of drug resistance and side effects. ${ }^{1,9,10}$ Given the limited ability of currently available treatments to deal with an influenza pandemic, there is an ongoing requirement for new approaches to reduce virus progression and transmission, especially for the development of anti-IFV agents offering broad spectrum protection.

Silver nanoparticles (AgNPs) have shown promising antibacterial and antifungal activity that is mainly due to inhibition of respiratory enzymes by release of Ag+ ions. ${ }^{11,12}$ AgNPs are increasingly being explored as antiviral agents in viral illnesses, such as human immunodeficiency virus-1, hepatitis B virus, herpes simplex virus type 1, Monkeypox virus, and Tacaribe virus. ${ }^{13-17}$ The mechanisms by which AgNPs exert their antiviral effects remain unclear. Recently, we demonstrated that AgNPs have efficient inhibitory effects against H1N1 influenza $A$ virus in Madin-Darby canine kidney (MDCK) cells. ${ }^{18}$ In this study, to determine whether these promising results can also be observed for different strains of IFV, we explored the therapeutic antiviral effects of AgNPs on H3N2 IFV both in vitro and in vivo. We used a series of in vitro assays to evaluate the ability of AgNPs to prevent virus infection in MDCK cells, and established an H3N2 IFV-infected mouse model to investigate their protective effects in vivo. The results demonstrate that AgNPs can interact with H3N2 IFV and efficiently prevent MDCK cells and mice from infection with the virus, suggesting that AgNPs could be of great interest in the application of antivirus offering broad spectrum protection.

\section{Materials and methods}

\section{Cells and virus}

MDCK cells purchased from the American Type Culture Collection (ATCC; Manassas, VA, USA) were maintained in Dulbecco's Modified Eagle's Medium (Gibco, Grand Island, NY, USA) supplemented with 10\% heatinactivated fetal bovine serum (Hyclone, Logan, UT, USA). The mouse-adapted influenza A virus (H3N2 subtype A/ Human/Hubei/3/2005) was kindly provided by Professor
Xulin Chen (Wuhan Institute of Virology, Chinese Academy of Science, Wuhan, People's Republic of China). The H3N2 IFV was propagated in 10-11-day-old embryonated chicken eggs, and egg allantoic fluids were harvested and stored at $-80^{\circ} \mathrm{C}$ until use for cell culture and inoculation of mice.

\section{Preparation of AgNPs}

Spherical AgNPs were obtained via an oxidation-reduction reaction by adding silver nitrate $(2 \mathrm{~mL}, 100 \mathrm{mM})$, sodium carbonate $(0.4 \mathrm{~mL}, 120 \mathrm{mM})$, and tannic acid $(2 \mathrm{~mL}, 5.8 \mathrm{mM})$ to a final volume of $50 \mathrm{~mL}$ with distilled water, adjusting the final $\mathrm{pH}$ to 7.4 with $1 \mathrm{M} \mathrm{HCl}$ or $5 \mathrm{M} \mathrm{NaOH}$. The mixture was then refluxed with vigorous stirring for 2 hours until there was no visible change in the pale yellow color, indicating formation of AgNPs. The synthesis efficiency of silver was calculated by inductively coupled plasma optical emission spectrometry or by the following formula:

$$
1-\frac{\text { Free silver in the synthesized solution }}{\text { Total silver used for synthesizing }} \times 100 \%
$$

\section{Cell viability assay}

The toxic effects of AgNPs and the solvent used for their AgNP preparation were determined by the Mosmann-based 3-(4,5-dimethylthiazol-2-yl)-2,5-diphenyltetrazolium bromide (MTT) assay, as in our recent publication. ${ }^{18}$ Based on the results, the solvent and AgNPs at concentrations ranging from $6.25 \mu \mathrm{g} / \mathrm{mL}$ to $50 \mu \mathrm{g} / \mathrm{mL}$ had no significant toxic effect on cells. In this study, three concentrations, ie, $12.5,25$, and $50 \mu \mathrm{g} / \mathrm{mL}$, were used for further assays. For the cell viability assay, H3N2 IFV was treated with AgNPs for 2 hours prior to infection using MDCK cells for a further 2 hours. H3N2 IFV control and solvent groups were included as controls after 48 hours of normal incubation ( $n=5$ in each group). Cell viability was evaluated by MTT assay and cytopathic effects (CPEs) were observed under light microscopy.

\section{Hemagglutination assay}

To determine the effects of AgNPs on IFV growth, MDCK cells were infected with $\mathrm{H} 3 \mathrm{~N} 2 \mathrm{IFV}$ that was pretreated with AgNPs $(12.5,25$, or $50 \mu \mathrm{g} / \mathrm{mL})$ for 2 hours. As an indicator of growth and replication of the virus and increased hemagglutination activity, the cell culture supernatants were harvested after 48 hours of incubation to measure hemagglutinin titers in 96-well microplates with V-shaped bottoms, as described elsewhere. ${ }^{18}$ An equal volume 
of $0.5 \%$ chicken erythrocytes suspended in phosphatebuffered saline and cell supernatants was incubated at room temperature for 1 hour. Viral titers are presented as $\log _{10} / \mathrm{mL}$. The assay was triplicated containing the IFV and solvent controls.

\section{Flow cytometry analysis}

It has been reported that IFV can induce cell apoptosis. ${ }^{19}$ The protective effects of AgNPs against cell apoptosis induced by H3N2 IFV were determined using flow cytometry. MDCK cells were infected with a mixture of $\mathrm{H} 3 \mathrm{~N} 2$ virus and $\mathrm{AgNPs}$ $(12.5,25$, or $50 \mu \mathrm{g} / \mathrm{mL})$ for 1 hour at $4^{\circ} \mathrm{C}$. Following two rinses with ice-cold phosphate-buffered saline and incubation of binding buffer (phosphate-buffered saline containing 10\% fetal bovine serum, $0.1 \mathrm{mg} / \mathrm{mL}$ transfer RNA and $0.1 \mathrm{mg} / \mathrm{mL}$ bovine serum albumin) for 30 minutes at room temperature, propidium iodide was added and incubated for 30 minutes at $4^{\circ} \mathrm{C}$ with protection from light. The cells were then washed three times, resuspended in $150 \mu \mathrm{L}$ of phosphate-buffered saline, and subjected to flow cytometric analysis. The preinfection group (cells infected with virus for 2 hours then incubated with $50 \mu \mathrm{g} / \mathrm{mL} \mathrm{AgNPs} \mathrm{for} \mathrm{a} \mathrm{further} 2$ hours) and post-infection group (cells incubated with $50 \mu \mathrm{g} / \mathrm{mL}$ AgNPs for 2 hours then infected with virus for a further 2 hours) were also performed for determining the cell apoptosis in parallel. The assay was triplicated containing the IFV and solvent controls.

\section{Immunofluorescence analysis}

MDCK cells $\left(1 \times 10^{5}\right)$ were seeded onto cover slips at $37^{\circ} \mathrm{C}$ for 24-48 hours followed by infection with a mixture of H3N2 IFV and $50 \mu \mathrm{g} / \mathrm{mL} \mathrm{AgNPs} \mathrm{for} 2$ hours. The same assay was done in parallel with the different groups, ie, the nontreated cell group, IFV control group, the solvent control group, preinfection group (infected with virus for 2 hours then incubated with $50 \mu \mathrm{g} / \mathrm{mL}$ AgNPs for a further 2 hours) and post-infection group (cells incubated with $50 \mu \mathrm{g} / \mathrm{mL}$ AgNPs for 2 hours then infected with virus for a further 2 hours). When the IFV control group developed significant lesions, the cells were fixed with $4 \%$ glutaraldehyde for 1 hour followed by blocking with $0.5 \%$ bovine serum albumin in phosphate-buffered saline for another hour at room temperature. Following two rinses with cold phosphate-buffered saline, the cells were stained with antihemagglutinin isothiocyanate-conjugated antibody (Dako Cytomation, England) for 60 minutes at $37^{\circ} \mathrm{C}$. The screening reagent was then added and incubated for 30 minutes. The slides were mounted and visualized under a fluorescence microscope (Olympus, Center Valley, PA, USA).

\section{Transmission electron microscopic analysis}

To illustrate the interaction between AgNPs and H3N2 IFV, AgNP-treated H3N2 IFV was negatively stained and morphologically analyzed using a transmission electron microscope (TEM; Hitachi, Tokyo, Japan). ${ }^{20}$ Following treatment of the H3N2 IFV with $50 \mu \mathrm{g} / \mathrm{mL}$ AgNPs at various time points (30, 60, and 120 minutes), the mixture was attached to the top of carbon-coated collodion grids (300 mesh; Nisshin EM Co., Ltd., Tokyo, Japan) for 10 minutes. The grids were stained with $2 \%$ phosphotungstic acid in Sorensen phosphate buffer (0.06 M, pH 6.5) for 2 minutes. After rinsing and air-drying the slides, the grids were examined by TEM.

\section{In vivo study}

Thirty-two 8-10-week-old female BALB/c mice (Laboratory Animal Centre of Dalian Medical University, Dalian, People's Republic of China) were randomly divided into four groups, ie, a phosphate-buffered saline control group, an H3N2 IFV control group, and two post-treatment groups of AgNPs and oseltamivir (used as positive controls). All mice in the IFV control, AgNP, and oseltamivir treatment groups were anesthetized and infected intranasally with $20 \mu \mathrm{L}$ of H3N2 IFV. AgNPs and oseltamivir were administered to the anesthetized mice initially 24 hours after infection and every 24 hours thereafter for a total of three times at concentrations of $5 \mathrm{mg} / \mathrm{kg}$ and $20 \mathrm{mg} / \mathrm{kg}$, respectively, via intranasal absorption. Clinical signs, changes in body weight, and mortality were recorded daily up to day 14 . Mice in the IFV control group and the other three groups were sacrificed on day 6 by isoflurane overdose. The lungs were extracted, washed in $2 \mathrm{mM}$ ethylenediaminetetraacetic acid (EDTA) phosphate-buffered saline, and kept at $-80^{\circ} \mathrm{C}$ until further experiments. Parts of lung tissue were homogenized and administered intranasally for the second passage of mouse infection. All experiments were approved and guided by the Institutional Animal Care and Use Committee, School of Medicine, Dalian University.

\section{Lung ratio calculation and virus titers in mice}

Following sacrifice of the mice, three mice were chosen at random and their lungs were weighed for the lung index using the equation, (weight of the lung/weight of the mouse) $\times 100 \%$. Lung homogenates were centrifuged at $10,000 \mathrm{~g}$ for 10 minutes before the supernatant was collected for determination of virus titer by the standard hemagglutinin assay as described above. 


\section{Analysis of lung histology}

After sacrifice, the middle lobe of the right lung from each mouse was removed and fixed in $10 \%$ formaldehyde solution for 24-48 hours. The tissues were dehydrated in a graded ethanol series and embedded in paraffin. Sections were embedded in wax and cut into $5 \mu \mathrm{m}$ slices for hematoxylin and eosin staining, and pathologic changes were studied by light microscopy.

\section{Statistical analysis}

All data are shown as the mean \pm standard deviation. One-way analysis of variance was used to identify statistically significant differences between groups. Statistical significance was set at $P<0.05$.

\section{Results}

\section{Characterization and stability of AgNPs}

The AgNPs generated in this study were assessed by TEM, with multiple TEM images chosen at random and over 300 nanoparticles measured to determine their size. The monodispersed AgNPs had a mean diameter of around $9.5 \mathrm{~nm}$ with a standard deviation of approximately $0.8 \mathrm{~nm}$ on observation by TEM (Figure 1). The synthesis efficiency of pure silver was around $99.99 \%$, and final concentrations of AgNPs and silver were $400 \mu \mathrm{g} / \mathrm{mL}$ and $0.8 \mu \mathrm{g} / \mathrm{mL}$ respectively. The AgNPs had a very narrow size distribution and were found to be stable over 6 months at room temperature without obvious particle precipitation.

\section{Inhibitory effects of AgNPs against $\mathrm{H} 3 \mathrm{~N} 2$ IFV}

To study the inhibitory effects of AgNPs against H3N2 IFV, percentages of surviving MDCK cells were determined by MTT assay. Following treatment of the virus with AgNPs at different concentrations $(12.5,25$, or $50 \mu \mathrm{g} / \mathrm{mL})$ for 2 hours before incubation with MDCK cells for 2 hours, the cell viability was $53.46 \% \pm 2.98 \%, 68.23 \% \pm 5.11 \%$, and $80.27 \% \pm 1.43 \%$, respectively, following 48 hours of normal incubation (Figure 2A), while the survival rates were $21.66 \% \pm 4.72 \%$ and $23.92 \% \pm 6.32 \%$, respectively, in the IFV control cells and cells treated with a mixture of virus and solvent. The data from the AgNP groups and those from the IFV control group were significantly different $(P<0.01)$. In addition, the anti-H3N2 IFV effects of the AgNPs were observed under a light microscope, and no significant CPEs were observed either in the normal cell group (Figure 2B) or the solvent cell group (Figure 2C), indicating that the solvent used for the AgNPs was not toxic to MDCK cells.

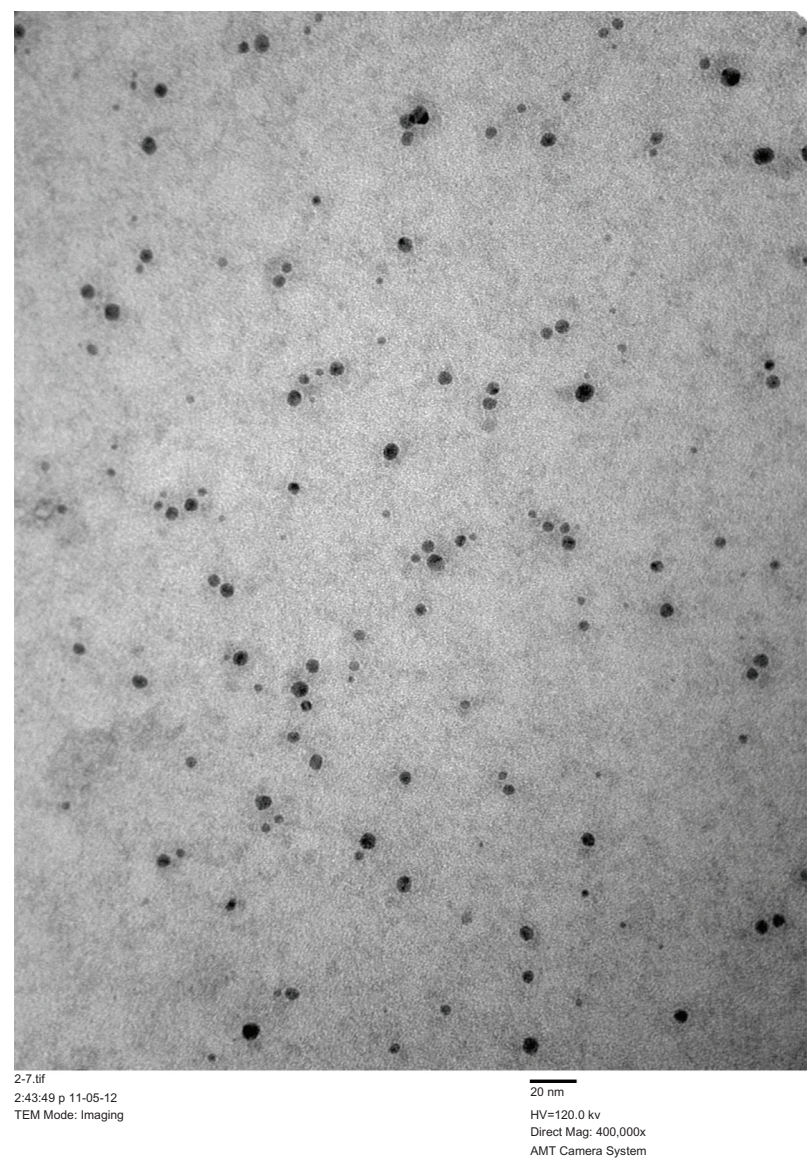

Figure I TEM analysis of silver nanoparticles.

Notes: Scale bar, $20 \mathrm{~nm}$; TEM magnification 400,000x.

Abbreviation: TEM, transmission electron microscopy.

However, typical CPEs were observed in the IFV control group (Figure 2D) and in the cells treated with a mixture of H3N2 IFV and solvent (Figure 2E), the infected cell monolayer shrank and became round, broke off, detached from the cell culture flask, and floated in the medium. No significant CPEs were detected in cells infected with a mixture of virus and $50 \mu \mathrm{g} / \mathrm{mL}$ AgNPs (Figure 2F), indicating that AgNPs at this concentration had inhibitory effects on H3N2 IFV infection.

\section{AgNPs inhibit growth of IFV in vitro}

To understand further the protective effects of AgNPs, we determined the inhibitory effects of AgNPs on viral growth by hemagglutinin assay. The lowest concentration of AgNPs $(12.5 \mu \mathrm{g} / \mathrm{mL})$ resulted in an approximately two-fold statistically significant decrease in hemagglutinin activity compared with the IFV control ( $P<0.01$, Figure 3$)$. Greater decreases in hemagglutinin titer were observed with increasing concentrations of AgNPs, indicating that AgNPs could efficiently inhibit the growth of IFV in vitro. Hemagglutinin titers did 


\section{A}
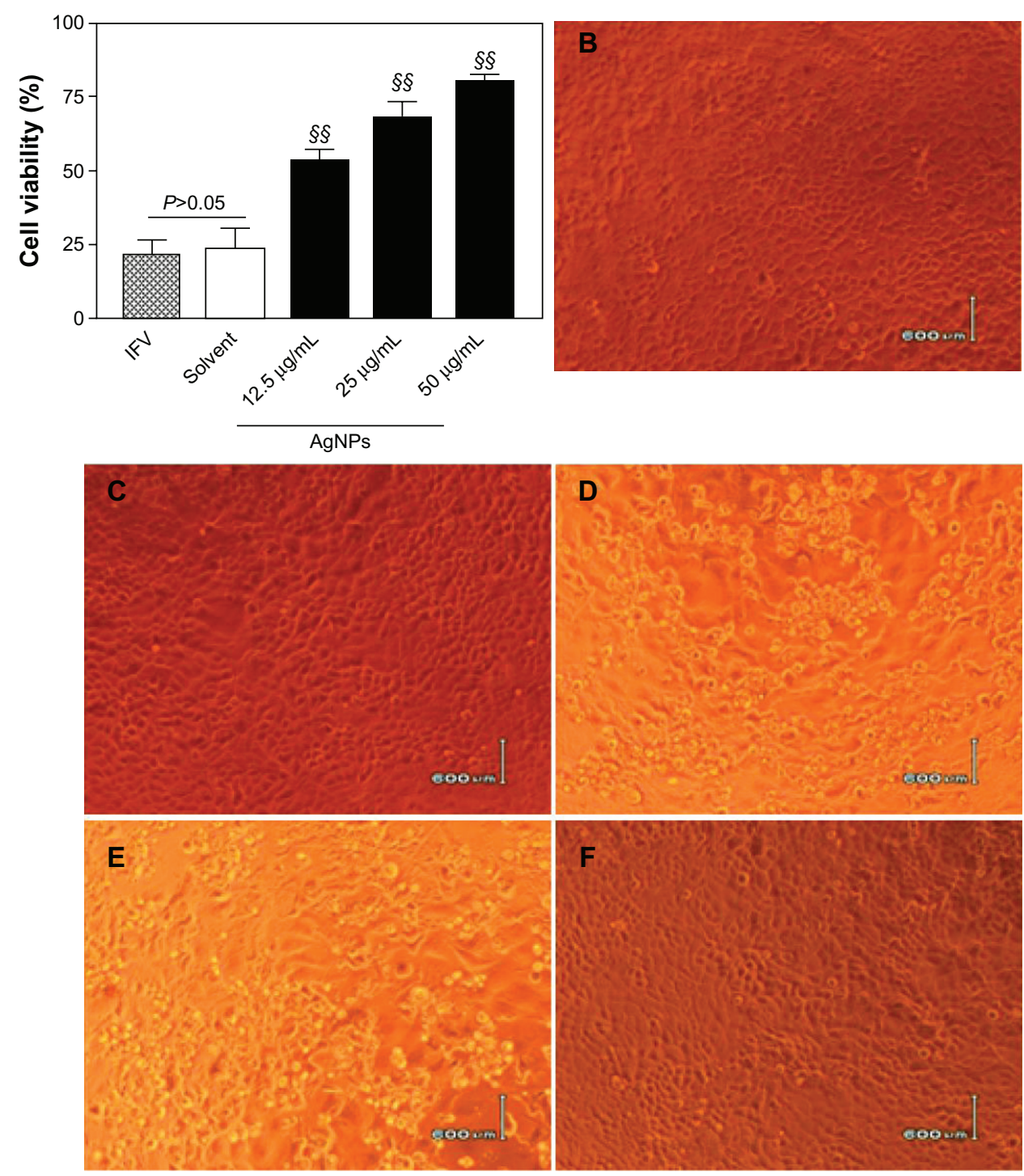

Figure 2 AgNPs inhibited H3N2 IFV infection of MDCK cells. (A) Treatment of H3N2 IFVs with AgNPs at different concentrations (I2.5, 25 , or $50 \mu g / \mathrm{mL}$ ) for 2 hours prior to incubation with MDCK cells for a further 2 hours. Survival percentages of MDCK cells were determined by MTT assay after 48 hours of normal incubation. IFV control and solvent group experiments were performed in parallel. (B-F) Cytopathic effects observed under light microscopy. No obvious cytopathic effect was observed in mock cells (B) and cells treated with the solvent used for AgNP preparation (C). Obvious cytopathic effects were observed in the IFV control (D) and cells treated with a mixture of the solvent and virus (E). Minor cytopathic effects were observed in cells treated with the mixture of $50 \mu \mathrm{g} / \mathrm{mL}$ AgNPs and virus (F).

Notes: Values shown are the mean \pm standard deviation for three independent experiments ( $\mathrm{n}=5$ in each group). The data are significantly different at $\$ \$ P<0.0 \mathrm{I}$ versus IFV control. Scale bar, $600 \mu \mathrm{m}$.

Abbreviations: AgNPs, silver nanoparticles; IFV, influenza virus; MDCK, Madin-Darby canine kidney; 3-(4,5-dimethylthiazol-2-yl)-2,5-diphenyltetrazolium bromide (MTT).

not differ between cells in the IFV control group and those in the mixture of virus and solvent group $(P>0.05$, Figure 3$)$. In addition, similar inhibitory effects were obtained when the mixture of H3N2 IFV and AgNPs was used to infect eggs (data not shown).

\section{Protective effects of AgNPs against cell apoptosis}

The apoptosis rate of normal cells was $6.31 \% \pm 2.16 \%$, while that in the IFV control cells and cells treated with the solvent and virus were $25.29 \% \pm 3.66 \%$ and $23.96 \% \pm 2.78 \%$, respectively (Figure 4). After treatment of the virus with AgNPs at different concentrations $(12.5,25$, or $50 \mu \mathrm{g} / \mathrm{mL}$ ) prior to incubation, apoptosis in MDCK cells was $17.15 \% \pm 4.35 \%, 12.47 \% \pm 2.52 \%$, and $8.27 \% \pm 3.26 \%$, respectively; these data showed statistically significant differences $(P<0.05$ versus IFV control). Further, the rate of apoptosis in the preinfection and post-infection groups was significantly different from that of the IFV control group $(13.58 \% \pm 4.86 \%$ and $17.47 \% \pm 5.13 \%$, respectively, $P<0.05$ ). 


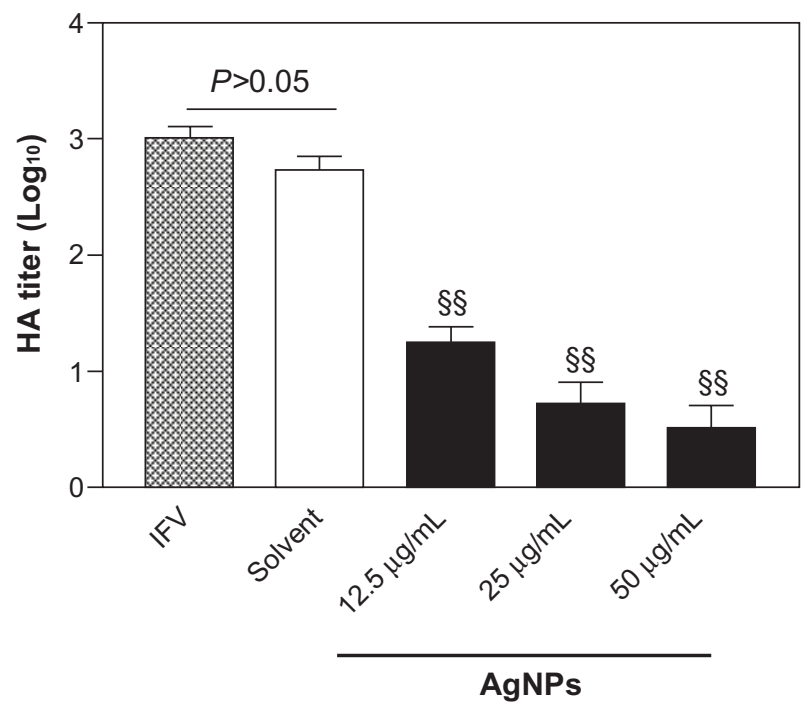

Figure $3 \mathrm{AgNPs}$ inhibited the growth of H3N2 IFV. Treatment of H3N2 IFVs with AgNPs at different concentrations $(12.5,25$, or $50 \mu \mathrm{g} / \mathrm{mL})$ for 2 hours prior to incubation with MDCK cells for 48 hours. Growth of the virus was examined by hemagglutinin assay. IFV control and the mixture of virus with the solvent experiments were performed in parallel.

Notes: Values shown are the mean \pm standard deviation for three independent experiments ( $n=5$ in each group). The data are significantly different at $\$ \$ p<0.0$ I versus IFV control.

Abbreviations: AgNPs, silver nanoparticles; IFV, influenza virus; MDCK, MadinDarby canine kidney. HA, hemagglutination.

These results suggest that AgNPs are able to reduce apoptosis induced by $\mathrm{H} 3 \mathrm{~N} 2 \mathrm{IFV}$ in MDCK cells.

\section{Analysis by immunofluorescence}

To investigate further whether AgNPs could affect infection of cells by the virus, an immunofluorescence staining assay was done on hemagglutinin protein. Normal cells showed no special color and had normal cellular structures (Figure 5A), while extensive specific yellow fluorescence was observed in the IFV control cells (Figure 5B) and in cells treated with the mixture of virus and solvent (Figure 5C). The cells rolled back, became rounded, detached, and fell from the flask. However, fluorescence was occasionally seen in cells infected with the mixture of AgNPs and H3N2 IFV (Figure 5D) and in the preinfection and post-infection groups (Figure $5 \mathrm{E}$ and $\mathrm{F}$ ). Overall, AgNPs show obvious anti-H3N2 IFV activity that might be due to their adsorption interference of H3N2 IFVs to MDCK cells.

\section{Morphologic abnormalities in AgNP-treated virus}

Negatively stained H3N2 IFV particles were observed by TEM to illustrate the interaction between AgNPs and IFV. The IFV control, approximately 80-120 nm, showed typical elliptical or spherically shaped normal IFVs containing viral
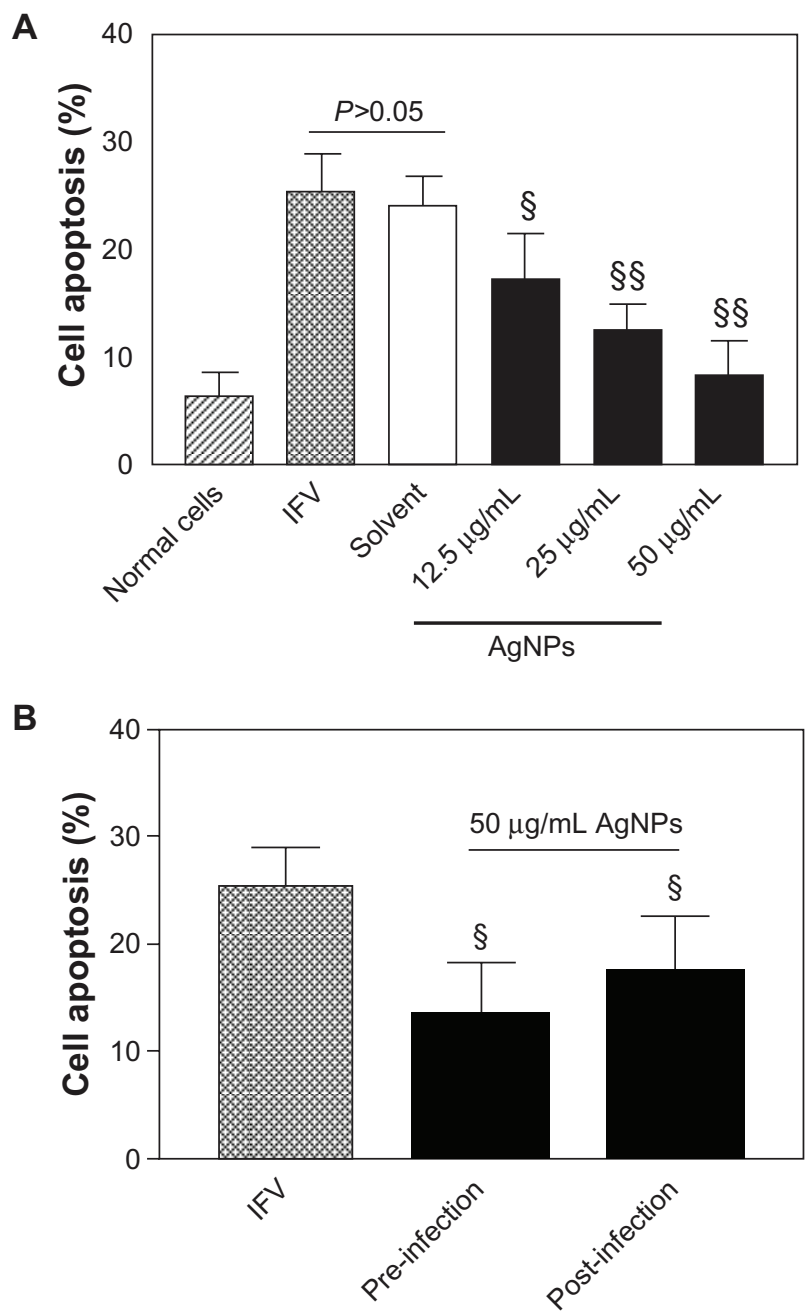

Figure 4 AgNPs reduced cell apoptosis induced by H3N2 IFV infection. (A) Treatment of H3N2 IFVs with AgNPs at different concentrations (I2.5, 25, or $50 \mu \mathrm{g} / \mathrm{mL}$ ) for 2 hours prior to incubation with MDCK cells for 48 hours. Cell apoptosis was determined by flow cytometry assay. IFV control and solvent group experiments were performed in parallel. (B) Cell apoptosis was detected after two treatment pathways: preinfection (cells infected with virus for 2 hours then incubated with $50 \mu \mathrm{g} / \mathrm{mL}$ AgNPs for a further 2 hours) and post-infection (cells were incubated with $50 \mu \mathrm{g} / \mathrm{mL}$ AgNPs for 2 hours then infected with virus for a further 2 hours).

Notes: Values shown are the mean \pm standard deviation for three independent experiments ( $n=5$ in each group). The data are significantly different at $\$ p<0.05$, $\$ \S P<0.0$ I versus IFV control.

Abbreviations: AgNPs, silver nanoparticles; IFV, influenza virus; MDCK, MadinDarby canine kidney.

matrix and capsid (Figure 6A). After interaction of AgNPs with H3N2 IFV for 30 minutes, the viral morphology changed slightly, with few AgNPs observed around the edge of the virus (Figure 6B); while parts of viral edges were lost after 60 minutes interaction between AgNPs and virus (Figure 6C). The viral morphologic structure was almost destroyed after 120 minutes of interaction (Figure 6D). These results show that AgNPs can interact directly with virus particles and destroy morphologic viral structures, leading to disruption of viral function in a time-dependent manner. 


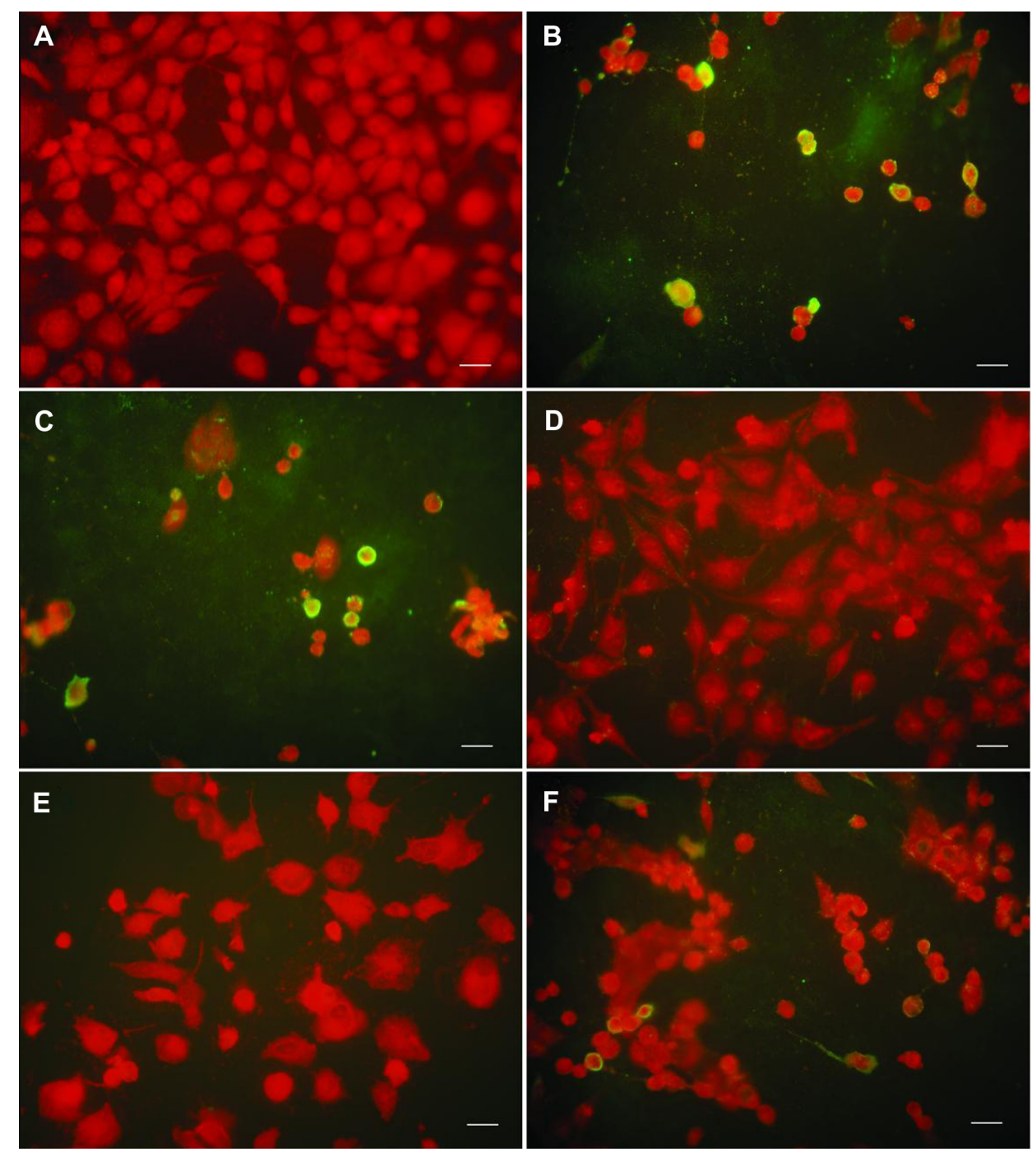

Figure 5 AgNPs inhibited H3N2 IFV binding on MDCK cells, as observed by immunofluorescence staining. (A) Mock cells. (B and C) Extensive fluorescence was observed in IFV control and cells treated with the mixture of virus and solvent, respectively. (D) Treatment of virus with $50 \mu g / \mathrm{mL} \mathrm{AgNPs} \mathrm{for} 2$ hours prior to incubation with MDCK

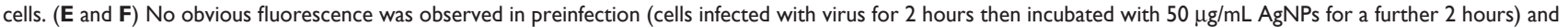
post-infection (cells were incubated with $50 \mu \mathrm{g} / \mathrm{mL} \mathrm{AgNPs} \mathrm{for} 2$ hours then infected with virus for a further 2 hours), respectively.

Note: Scale bar, $20 \mu \mathrm{m}$.

Abbreviations: AgNPs, silver nanoparticles; IFV, influenza virus; MDCK, Madin-Darby canine kidney.

\section{Inhibition of H3N2 IFV infection by AgNPs in vivo}

Morbidity and mortality were determined to examine the potential role of AgNPs in protection against H3N2 IFV infection in live animals. All mice in the IFV control group had died by day 7 after infection, and showed severe weight loss. In contrast, after only three cycles of treatment, the mice treated with AgNPs and oseltamivir had survival rates of $75 \%$ and $88 \%$, respectively, even though the surviving mice showed visible weight loss compared with the phosphatebuffered saline control group (Figure 7A and B). To understand better how AgNPs prevent IFV infection, the mouse lungs were harvested to detect lung ratios and virus titers.
The lung ratio in IFV-infected mice was approximately three times than that of the phosphate-buffered saline control (Figure 7C), and it showed minor changes in the AgNP and oseltamivir groups compared with the phosphate-buffered saline control group. The lung ratio is a reliable indicator of lung lesion levels; at high levels, the cellular inflammatory and cytosol permeating could increase inside of lung cells, resulting in cell edema and an increase in the lung ratio. ${ }^{21}$ The AgNP and oseltamivir groups showed a reduction in lung virus titers by $>2 \log _{10}$-fold compared with the IFV control (Figure 7D). This finding indicates that intranasal administration of AgNPs and oseltamivir can protect mice from H3N2 IFV infection. 

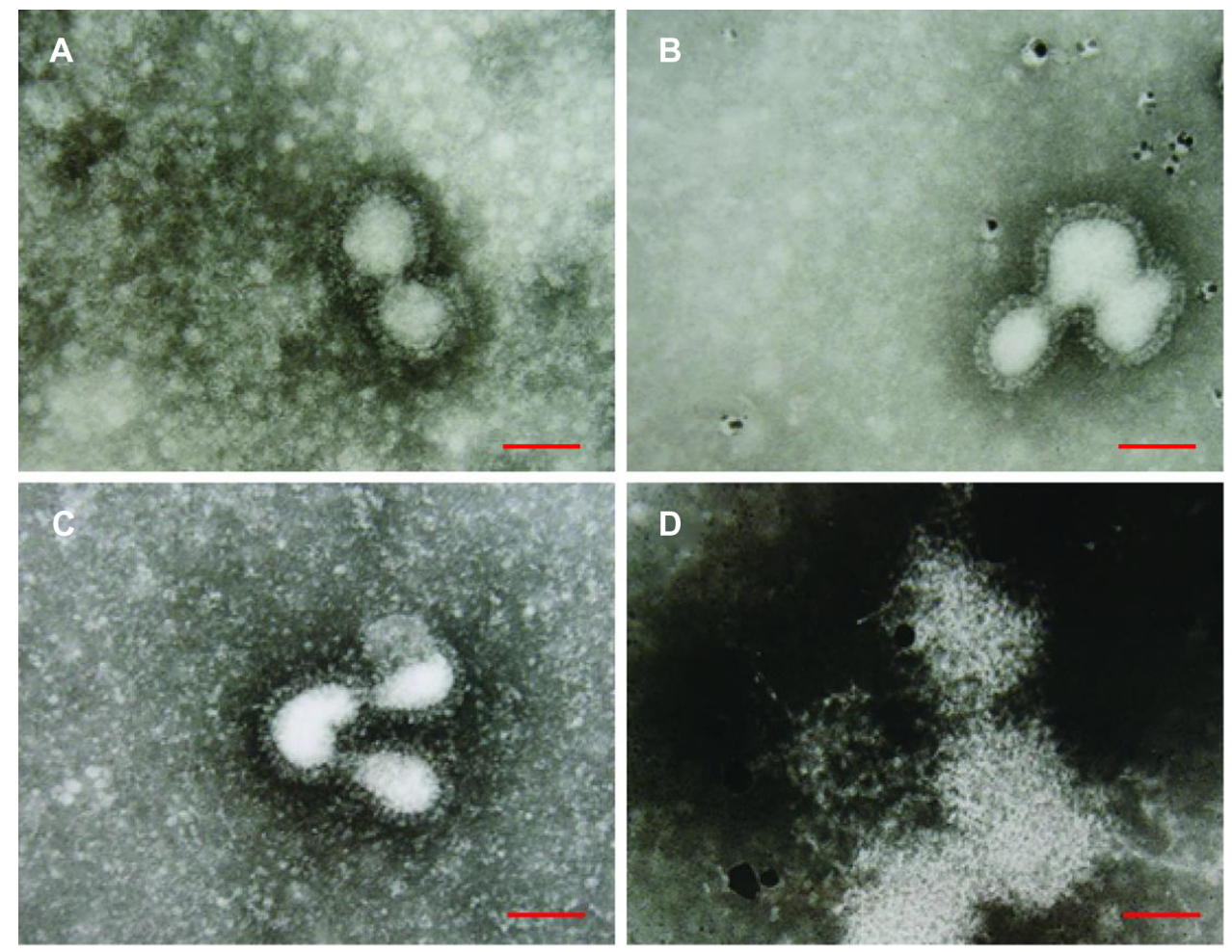

Figure 6 Transmission electron microscopic analysis of AgNPs-treated H3N2 IFV. Negative staining of viruses was analyzed. (A) Virus control. (B-D) Viral morphologic structures were gradually damaged when H3N2 IFV was treated with $50 \mu \mathrm{g} / \mathrm{mL}$ AgNPs for 30 minutes, 90 minutes, and I 20 minutes, respectively.

Note: Scale bar, $100 \mathrm{~nm}$

Abbreviations: AgNPs, silver nanoparticles; IFV, influenza virus.

In addition, pathologic tissue changes were examined by histologic analysis. Compared with the phosphate-buffered saline control group (Figure 7Ea), minor changes in the structure of the pulmonary alveolus were observed in the mice treated with oseltamivir (Figure 7Eb). In mice administered AgNPs, some lymphocytic infiltration was seen in the alveolar septum (Figure 7Ec), and this infiltration was more pronounced and accompanied by alveolar wall necrosis in mice infected with free IFV (Figure 7Ed). These results suggest that AgNPs can inhibit IFV transfection and replication in the mouse lung. We repeated our in vivo experiment and prepared lung homogenates for secondary passage in mice. Both AgNPs and oseltamivir were able to increase the percentage of surviving mice significantly at 2 weeks after infection (Table 1). Taken together, these data suggest that intranasal administration of AgNPs can protect mice from H3N2 IFV infection in vivo.

\section{Discussion}

An influenza pandemic is a serious threat to public health, but the antiviral agents currently used for influenza are weakened as a result of side effects and the increasing emergence of drug-resistant organisms during treatment. ${ }^{9}$
Vaccines also have their drawbacks, due to the requirement that they closely match the new virus strain, thereby killing the virus efficiently. ${ }^{8}$ Therefore, there is a high demand for new antiviral agents in the treatment and control of influenza. In the present study, we selected a highly pathogenic IFV strain, ie, H3N2, as the virus model and evaluated the antiviral effects of AgNPs on H3N2 IFV. To this end, we performed a series of in vitro assays based on cell culture and established an animal model of IFV infection in vivo, and demonstrated that AgNPs are potential therapeutics that can effectively inhibit IFV infection.

The MTT assay is commonly used to measure cell viability because of its sensitivity and rapid response. In this study, the viability of MDCK cells significantly increased and no obvious CPEs were observed when cells were incubated with a mixture of AgNPs and H3N2 IFV as compared with IFV control and the solvent group. These results demonstrate that AgNPs can prevent MDCK cells from infection by H3N2 IFV. In addition, on fluorescence staining analysis, no obvious fluorescence was observed in cells treated with AgNPs, which investigates that AgNPs may available to damage the structure of viral surface so as to inhibit virus attachment to host cells. Similarly, it has been shown that 

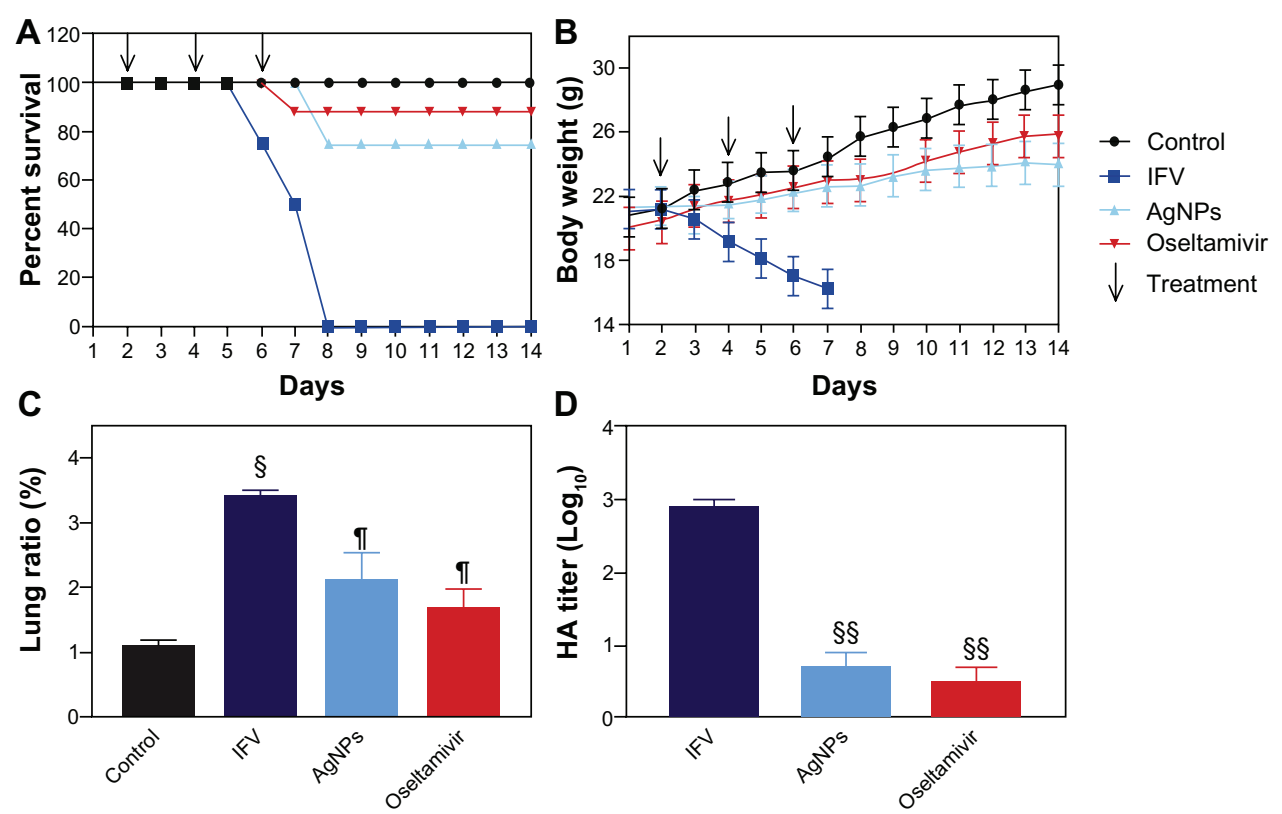

$E$

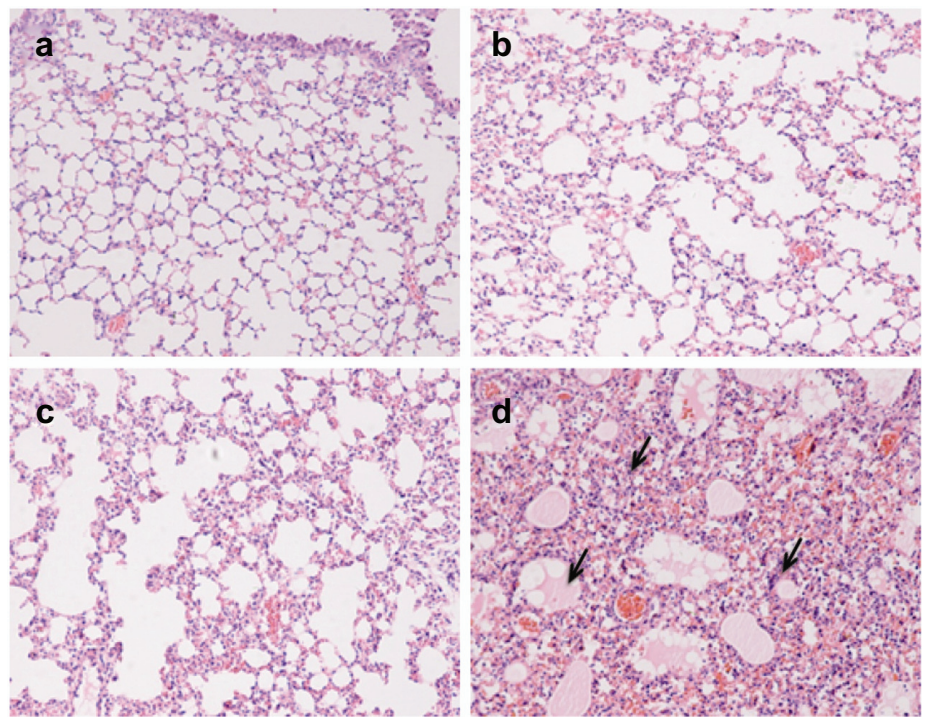

Figure 7 Intranasal AgNP administration protected the mice from infection with H3N2 IFV. (A) Survival rate changes (\%). (B) Changes in body weight (\%). (C and D) Lung ratio and titers at day 6 post-infection. (E) Pathologic lesions of lung tissues (a-d) represent mice treated with phosphate-buffered saline, oseltamivir, and AgNPs, and the virus control group, respectively). Arrows indicate lymphocytic infiltration BALB/c mice $(n=8)$ were infected with H3N2 IFV 24 hours prior to intranasal administration of AgNPs $(5 \mathrm{mg} / \mathrm{kg})$ and oseltamivir $(25 \mathrm{mg} / \mathrm{kg})$ on three occasions over a 24-hour interval. The survival rate and body weight changes were monitored daily. Growth of virus was examined by hemagglutination assay. Pathologic lung lesions were identified by histochemistry assay.

Notes: Values shown are the mean \pm standard deviation for three independent experiments (each group $n=8$ ). (C) The data are significantly different at ${ }^{\S} P<0.05$ and $\pi P>0.05$ versus the phosphate-buffered saline control. (D) The data are significantly different at ${ }^{\$} P<0.0$ I versus the IFV control.

Abbreviations: AgNPs, silver nanoparticles; IFV, influenza virus. HA, hemagglutination.

AgNPs can reduce formation of the virus plaque induced by Monkeypox virus. ${ }^{16}$

Influenza virus contains two main functional glycoproteins, ie, hemagglutinin and neuraminidase, that wrap around an inner core. ${ }^{22}$ The hemagglutinin protein, a structural component of the viral envelope, has hemagglutinating activity and contributes to identifying and binding to host membrane receptor sites, resulting in entry of the viral capsid and genome and infection of the host. ${ }^{23,24}$ Thus, the hemagglutinin protein might be of interest as a target for antiviral drugs. Treatment of H3N2 IFV with AgNPs resulted in marked reduction in virus hemagglutinin titers by up to more than two $\log _{10}$ when cells were incubated with a combination of AgNPs and H3N2 IFV. These results indicate that AgNPs could inhibit the growth of H3N2 IFV, and hemagglutination activity is likely to be involved in the mechanism of antiviral effects. AgNPs might interfere with binding of the viral hemagglutinin to cellular receptors and inhibit the viral entry 
Table I Protective effects of AgNPs on H3N2 IFV infected mice in secondary passage in vivo

\begin{tabular}{lllll}
\hline Groups & $\begin{array}{l}\text { Previous } \\
\text { injected dose }\end{array}$ & $\begin{array}{l}\text { Survivors/ } \\
\text { total }\end{array}$ & $\begin{array}{l}\text { Survival, } \\
\text { days }\end{array}$ & $\begin{array}{l}\text { Survival } \\
\text { (\%) }\end{array}$ \\
\hline IFV & Free & $0 / 8$ & 6 & 0 \\
$\mathrm{AgNPs}$ & $5 \mathrm{mg} / \mathrm{kg}$ & $8 / 8$ & 14 & 100 \\
Oseltamivir & $20 \mathrm{mg} / \mathrm{kg}$ & $8 / 8$ & 14 & 100 \\
\hline
\end{tabular}

Abbreviations: $\mathrm{H} 3 \mathrm{~N} 2$, A/Human/Hubei/3/2005; IFV, influenza virus; AgNPs, silver nanoparticles; IFV, influenza virus.

process, which is consistent with the observation that AgNPs can inhibit vaccinia virus infection by preventing entry of the virus into host cells via a macropinocytosis-dependent mechanism. ${ }^{25}$ Each hemagglutinin molecule has two disulfide bonds, which can be broken to expose receptor binding sites that are available for interacting with host cells. ${ }^{26}$ These exposed disulfide bonds are attractive sites for interaction between AgNPs and the virus, and thereby exhibit antiviral activity when the receptor binding sites are blocked by AgNPs. ${ }^{27}$ Consistent with the present study, other researchers have shown that AgNPs $1-10 \mathrm{~nm}$ in size are able to attach to the virus and bind to the exposed sulfur-bearing residues of gp120 glycoprotein, contributing to inhibition of binding between the virus and host cells. ${ }^{14}$ It has also been documented that AgNPs exert anti-human immunodeficiency virus activity by binding to gp 120 glycoprotein through the prevention of receptor-dependent virion binding, fusion, and infectivity, at both the early viral replication and post-entry stages. $^{28}$

To confirm further our findings in vitro, H3N2-infected mice were post-treated with AgNPs or oseltamivir on three occasions over a 24-hour interval, and lung virus titers were evaluated after the killing the mice. Post-treatment with AgNPs or oseltamivir resulted in significantly decreased lung viral titers compared with titers in untreated mice (approximately 3 -fold $\log _{10}$ ). This obvious control of lung viral replication indicates that AgNPs may play an important role in inhibiting virus growth in vivo compared with oseltamivir, suggesting that AgNPs may have an obvious anti-H3N2 effect in vivo. In support of this conclusion, lung homogenates were collected and subpassaged into mice via intranasal infection. Mice infected with lung homogenates derived from mice treated with AgNPs and oseltamivir were able to maintain a longer life than that of the free IFV infected mice. In this regard, our data demonstrate that intranasal administration of AgNPs is able to posit AgNPs act as a strong virucidal agent in vivo for prevention of $\mathrm{H} 3 \mathrm{~N} 2$ virus infection.

Influenza viral envelopes are largely derived from host cell membranes, and functionally served for viral entrance to host cells. ${ }^{29}$ To this end, the disruption of viral envelopes and capsids may help to detach virion binding to the cell surface, resulting in disinfection of viruses to the host. In this study, negative staining of AgNPs-treated H3N2 viruses was morphologically analyzed. It was found that most of the $\mathrm{H} 3 \mathrm{~N} 2$ viral structures were ill-defined after treatment with AgNPs from 30 minutes to 2 hours. These results suggest that AgNPs may have a negative impact on entry of the virus into host cells. AgNPs may directly interact with H3N2 viral capsid proteins and thereby inhibit receptor-mediated viral binding and endocytosis. Consistent with our study, Speshock et al reported that AgNPs can bind to viral glycoproteins and inactivate viral functions prior to interaction with host cells. ${ }^{17}$ In addition, round AgNPs $10 \mathrm{~nm}$ in diameter could block the binding and penetration of Monkeypox virus into host cells. ${ }^{16}$ The change in H3N2 morphology may provide a possible mechanism that the effect of AgNPs on IFV particles might be virucidal rather than antiviral, thereby contributing to the interference of virus binding, diffusing, and further replication by AgNPs.

AgNPs have been known to be effective in inhibiting various viruses in vitro, while the in vivo effects of AgNPs on influenza virus infection remain largely unknown. In this study, we investigated the inhibitory effects of AgNPs on influenza virus via intranasal delivery using an $\mathrm{H} 3 \mathrm{~N} 2$ virus-infected mouse model. The protection of AgNPs post-treatment via intranasal administration was strong indicating the significant resistance of AgNPs to H3N2 virus infection. AgNP-treated mice did not show obvious illness symptoms even though minor body weight loss was observed. Intranasal administration of AgNPs and oseltamivir to $\mathrm{H} 3 \mathrm{~N} 2$ virus-infected mice had a significant survival benefit, and only minor pathologic lesions were seen in lung tissues. It was reported that daily use of ginseng could significantly increase vaccination efficiency and reduce cases of influenza symptoms. ${ }^{1}$ Further studies should explore whether a combination of AgNPs and vaccination could improve the live efficacy against influenza infection. The molecular mechanism underlying the antiviral activity of AgNPs remains unknown. Soluble $\mathrm{Ag}^{+}$ions can strongly inhibit growth of pathogens by downregulation of respiratory enzymes, suppression of electron transport components, and interference with the functions of DNA. ${ }^{30}$ The results of the present study suggest that AgNPs possess multiple mechanisms acting against IFV infection by acting either as direct virucidal particles or antiviral agents. Further study of the antiviral mechanics involved is required. 


\section{Conclusion}

In this study, we used H3N2 IFV as a virus model to investigate the inhibitory activity of AgNPs against the influenza virus by performing a series of assays in vitro (MTT, hemagglutinin, flow cytometry, immunofluorescence, and TEM) and in vivo (an IFV-infected mouse model). In vitro, AgNPs significantly protected cells against viral infection by increasing their live viability and protecting against CPEs, inhibiting growth of the virus, and decreasing the cellular apoptosis induced by H3N2 IFV. AgNPs interacted with viral particles and destroyed their morphologic structures in a time-dependent manner. In addition, intranasal AgNP administration significantly enhanced survival in mice, prevented virus growth in their lungs, inhibited the development of pathologic lung lesions, and had a marked survival benefit on secondary passage. Taken together, the results indicate that AgNPs have promising antiviral activity against H3N2 IFV through multiple mechanisms, demonstrating that development of optimized AgNPs and further investigation of their relevant antiviral mechanisms will be critical for controlling influenza outbreaks.

\section{Acknowledgments}

This study was supported by a grant from the National Natural Science Foundation of China (30870681). We thank Professor Xu-lin Chen (Wuhan Institute of Virology, Chinese Academy of Sciences) for kindly providing the A/Human/ Hubei/3/2005 (H3N2) influenza virus used in this work.

\section{Disclosure}

The authors report no conflicts of interest in this work.

\section{References}

1. Yoo DG, Kim MC, Park MK, et al. Protective effect of Korean red ginseng extract on the infections by $\mathrm{H} 1 \mathrm{~N} 1$ and $\mathrm{H} 3 \mathrm{~N} 2$ influenza viruses in mice. J Med Food. 2012;15(10):855-862.

2. Li W, Yang X, Jiang Y, et al. Inhibition of influenza A virus replication by RNA interference targeted against the PB1 subunit of the RNA polymerase gene. Arch Virol. 2011;156(11):1979-1987.

3. Neumann G, Noda T, Kawaoka Y. Emergence and pandemic potential of swine-origin H1N1 influenza virus. Nature. 2009;459(7249): 931-939.

4. Lynch JP 3rd, Walsh EE. Influenza: evolving strategies in treatment and prevention. Semin Respir Crit Care Med. 2007;28(2):144-158.

5. Tharakaraman K, Raman R, Stebbins NW, Viswanathan K, Sasisekharan V, Sasisekharan R. Antigenically intact hemagglutinin in circulating avian and swine influenza viruses and potential for H3N2 pandemic. Sci Rep. 2013;3:1822.

6. Donnelly JJ, Friedman A, Martinez D, et al. Preclinical efficacy of a prototype DNA vaccine: enhanced protection against antigenic drift in influenza virus. Nat Med. 1995;1(6):583-587.

7. Webster RG, Laver WG, Air GM, Schild GC. Molecular mechanisms of variation in influenza viruses. Nature. 1982;296(5853): 115-121.
8. Peyre M, Fusheng G, Desvaux S, Roger F. Avian influenza vaccines: a practical review in relation to their application in the field with a focus on the Asian experience. Epidemiol Infect. 2009;137(1):1-21.

9. Poland GA, Jacobson RM, Ovsyannikova IG. Influenza virus resistance to antiviral agents: a plea for rational use. Clin Infect Dis. 2009;48(9):1254-1256.

10. Haidari M, Zhang W, Ganjehei L, Ali M, Chen Z. Inhibition of MLC phosphorylation restricts replication of influenza virus - a mechanism of action for anti-influenza agents. PLoS One. 2011;6(6):e21444.

11. Mori Y, Ono T, Miyahira Y, Nguyen VQ, Matsui T, Ishihara M. Antiviral activity of silver nanoparticle/chitosan composites against H1N1 influenza A virus. Nanoscale Res Lett. 2013;8(1):93.

12. Tyler WJ, Petzold GC, Pal SK, Murthy VN. Experience-dependent modification of primary sensory synapses in the mammalian olfactory bulb. J Neurosci. 2007;27(35):9427-9438.

13. Baram-Pinto D, Shukla S, Perkas N, Gedanken A, Sarid R. Inhibition of herpes simplex virus type 1 infection by silver nanoparticles capped with mercaptoethane sulfonate. Bioconjug Chem. 2009;20(8):1497-1502.

14. Elechiguerra JL, Burt JL, Morones JR, et al. Interaction of silver nanoparticles with HIV-1. J Nanobiotechnology. 2005;3:6.

15. Lu L, Sun RW-Y, Chen R, et al. Silver nanoparticles inhibit hepatitis B virus replication. Antivir Ther. 2008;13(2):253-262.

16. Rogers JV, Parkinson CV, Choi YW, Speshock JL, Hussain SM. A preliminary assessment of silver nanoparticle inhibition of Monkeypox virus plaque formation. Nanoscale Res Lett. 2008;3(4):129-133.

17. Speshock JL, Murdock RC, Braydich-Stolle LK, Schrand AM, Hussain SM. Interaction of silver nanoparticles with Tacaribe virus. J Nanobiotechnology. 2010;8:19.

18. Xiang DX, Chen Q, Pang L, Zheng CL. Inhibitory effects of silver nanoparticles on H1N1 influenza A virus in vitro. J Virol Methods. 2011;178(1-2):137-142.

19. Takizawa T, Matsukawa S, Higuchi Y, Nakamura S, Nakanishi Y, Fukuda R. Induction of programmed cell death (apoptosis) by influenza virus infection in tissue culture cells. J Gen Virol. 1993 74 Pt 11:2347-2355.

20. Bradley DE. A study of the negative staining process. J Gen Microbiol. 1962;29:503-516.

21. Li HD, Zhang ZR, Zhang QX, Qin ZC, He DM, Chen JS. Treatment with exogenous hydrogen sulfide attenuates hyperoxiainduced acute lung injury in mice. Eur J Appl Physiol. 2013;113(6): 1555-1563.

22. Eckert EA. Influenza virus envelope protein: biological activity as a function of reassociation. Science. 1967;158(3800):527.

23. Wilson JC, von Itzstein M. Recent strategies in the search for new anti-influenza therapies. Curr Drug Targets. 2003;4(5):389-408.

24. Eckert EA. Envelope protein of influenza virus. I. Hemagglutinating activity of reassociated subunits. J Virol. 1967;1(5):920-927.

25. Trefry JC, Wooley DP. Silver nanoparticles inhibit vaccinia virus infection by preventing viral entry through a macropinocytosis-dependent mechanism. J Biomed Nanotechnol. 2013;9(9):1624-1635.

26. Bullough PA, Hughson FM, Skehel JJ, Wiley DC. Structure of influenza haemagglutinin at the $\mathrm{pH}$ of membrane fusion. Nature. 1994;371(6492): $37-43$.

27. Radyukhin V, Fedorova N, Ksenofontov A, Serebryakova M, Baratova L. Cold co-extraction of hemagglutinin and matrix M1 protein from influenza virus A by a combination of non-ionic detergents allows for visualization of the raft-like nature of the virus envelope. Arch Virol. 2008;153(10):1977-1980.

28. Lara HH, Ayala-Nunez NV, Ixtepan-Turrent L, Rodriguez-Padilla C. Mode of antiviral action of silver nanoparticles against HIV-1. J Nanobiotechnology. 2010;8:1

29. Boni MF, Gog JR, Andreasen V, Feldman MW. Epidemic dynamics and antigenic evolution in a single season of influenza A. Proc Biol Sci. 2006;273(1592):1307-1316.

30. Li Y, Leung P, Yao L, Song QW, Newton E. Antimicrobial effect of surgical masks coated with nanoparticles. J Hosp Infect. 2006;62(1): 58-63. 


\section{Publish your work in this journal}

The International Journal of Nanomedicine is an international, peerreviewed journal focusing on the application of nanotechnology in diagnostics, therapeutics, and drug delivery systems throughout the biomedical field. This journal is indexed on PubMed Central, MedLine, CAS, SciSearch ${ }^{\circledR}$, Current Contents ${ }^{\circledR} /$ Clinical Medicine,

Journal Citation Reports/Science Edition, EMBase, Scopus and the Elsevier Bibliographic databases. The manuscript management system is completely online and includes a very quick and fair peer-review system, which is all easy to use. Visit http://www.dovepress.com/ testimonials.php to read real quotes from published authors.

Submit your manuscript here: http://www.dovepress.com/international-journal-of-nanomedicine-journal 